Archives de sciences sociales des religions

192 | octobre-décembre 2020

Bulletin bibliographique

\title{
Vassili GRIGOROVITCH-BARSKI, Pérégrinations (1723-1741)
}

Traduit du russe par Myriam Odayski, Genève, Éditions des Syrtes, 2019, $554 \mathrm{p}$.

Bernard Heyberger

\section{OpenEdition}

Journals

Édition électronique

URL : http://journals.openedition.org/assr/57672

DOI : $10.4000 /$ assr. 57672

ISSN : $1777-5825$

Éditeur

Éditions de l'EHESS

Édition imprimée

Date de publication : 31 décembre 2020

Pagination : 221-223

ISBN : 978-2-7132-2826-1

ISSN : 0335-5985

Référence électronique

Bernard Heyberger, «Vassili grigonovitch-Barski, Pérégrinations (1723-1741) 》, Archives de sciences sociales des religions [En ligne], 192 | octobre-décembre 2020, mis en ligne le 31 décembre 2020 consulté le 22 janvier 2021. URL : http://journals.openedition.org/assr/57672 ; DOI : https://doi.org/ 10.4000/assr. 57672

Ce document a été généré automatiquement le 22 janvier 2021.

(c) Archives de sciences sociales des religions 


\section{Vassili GRIGOROVITCH-BARSKI, Pérégrinations (1723-1741)}

Traduit du russe par Myriam Odayski, Genève, Éditions des Syrtes, 2019, $554 \mathrm{p}$.

\section{Bernard Heyberger}

\section{RÉFÉRENCE}

Vassili GRIGOROVITCH-BARSKI, Pérégrinations (1723-1741), traduit du russe par Myriam Odayski, Genève, Éditions des Syrtes, 2019, 554 p.

1 Le récit de Vassili Grigorovitch-Barski, après avoir connu un succès éditorial au XIX ${ }^{e}$ siècle, est tombé dans l'oubli. La traduction française est fondée sur une édition russe récente. On peut se réjouir que Myriam Odaysky ait mis ce texte à la disposition des lecteurs francophones, car il ne s'agit pas seulement d'une source documentaire incomparable sur les nombreux lieux visités : des passages plus intimes révèlent aussi une personnalité attachante, singulière, en même temps qu'exemplaire d'une époque et d'une culture.

2 Comme d'autres récits de voyage slaves ou arabes, celui-ci représente une nouvelle littérature typique du XVIII ${ }^{e}$ siècle, produite par des non lettrés, qui ne s'adressent pas prioritairement à des lettrés, et qui se livrent à une écriture très autocentrée, en prenant le lecteur à témoin. À partir de son expérience personnelle, Barski fournit quantité d'informations sur l'art de voyager en mendiant au XVIII siècle. Relevons par exemple l'importance de collectionner les patentes des autorités sur son chemin, pour être reconnu comme pèlerin, pouvoir circuler librement et bénéficier de l'hospitalité dans des structures dédiées ou chez des particuliers. La qualité de l'accueil dans un lieu semble plus dépendante de la conjoncture économique que de la confession des habitants: il lui arrive d'être bien traité par des catholiques et malmené par des orthodoxes. Retenons aussi tous les détails sur la navigation en Méditerranée, les itinéraires et leur durée aléatoire, les attaques des corsaires catholiques sur les navires 
des ressortissants ottomans (chrétiens), et la prédominance des bateaux français dans les liaisons maritimes.

3 L'auteur, issu d'un milieu aisé, a étudié « dans les classes latines » instituées à Kiev par le métropolite Pierre Mohyla en 1633, sur le modèle jésuite. Il y poursuivit le cursus jusqu'à la philosophie. Il quitta Kiev à 22 ans pour continuer ses études chez les jésuites à Lvov, en Pologne, contre l'avis de son père, qui préférait le russe au latin, la pratique religieuse à la science, et qui essaya de le retenir. L'expérience fut de courte durée, et marqua le début d'une errance qui se fixa d'abord pour but la visite des reliques de saint Nicolas à Bari (Pouilles).

Barski est suffisamment instruit pour prendre des notes pendant son voyage, et restituer ainsi des détails précis sur les distances et les lieux visités. Il fait preuve d'une très grande minutie dans la description des architectures et des paysages. Il déchiffre des inscriptions sur les bâtiments. Il visite des lieux rarement décrits par des voyageurs de cette époque, comme la région du Hauran, au sud de Damas. Aussi est-il une source précieuse, notamment sur le monachisme orthodoxe en Grèce, à Chypre, en Palestine et en Syrie. De plus, il a un goût pour le dessin, et illustre son texte de belles représentations d'un certain nombre de lieux visités, qui montrent sa maîtrise du plan et de la perspective. L'édition française reproduit 32 des 148 dessins réalisés.

5 La culture de l'auteur est d'abord biblique: le texte est truffé de références scripturaires, généralement précises, et sa géographie de la Terre sainte est celle des Évangiles. Sa culture est aussi liturgique : durant tout son périple, Barski note le déroulement des offices grecs, les variations dans leur déroulement, les pratiques linguistiques spécifiques. Il est familier de la liturgie byzantine, même récitée dans une langue qu'il ignore, et peut suivre le culte sans difficulté. Cette aptitude à s'associer à l'office est le principal marqueur de son identité orthodoxe, avec la pratique du jeûne, sur laquelle il se montre sans compromis, parfois au péril de sa vie, lorsqu'il chemine le ventre vide.

6 Sa culture latine est utile au pèlerin. Au début de son voyage, le latin lui sert de langue de communication, y compris avec le patriarche orthodoxe de Jérusalem Chrysanthe Notaras, qu'il rencontre à Chios en août 1725 (p. 145-146). Dans la première partie de ses pérégrinations, par Vienne et Budapest jusqu'en Italie, qu'il visite longuement, il admire le style des édifices religieux latins, assiste aux offices sans trouble ni réticence. À Rome, il loge à l'hospice de la Trinité, qui accueille les pèlerins catholiques, en se faisant passer pour polonais. Il n'hésite pas à se confesser (" feignant et dissimulant ») afin d'obtenir le certificat nécessaire pour être admis à prendre un repas avec le pape (p. 88). Ce qui ne l'empêche pas à l'occasion de recourir à des stéréotypes pour dénoncer «les Latins superbes et pleins de ruse" et recommander d'éviter d'embarquer « avec des Romains » (p. 133-134).

7 Sa géographie mentale se concentre sur la Méditerranée orientale, sur l'ancien Empire byzantin, dont il invoque les souverains fondateurs. Il semble d'ailleurs croire que l'Empire romain, et la ville de Rome elle-même, est de fondation hellène (p. 90, 97). En Orient, il a de multiples occasions de déplorer la disparition de l'empire lorsqu'il visite des sites sous autorité ottomane, parfois confisqués par les musulmans.

8 Éduqué dans une culture mixte, latine et byzantine, ayant expérimenté des situations de pluralisme confessionnel à Kiev et à Lvov, puis pendant sa traversée de l'Europe, il semble se confessionnaliser progressivement durant son périple, prenant de plus en plus conscience de son identité orthodoxe, à un moment où justement les identités se 
crispent. Il s'est pris de goût pour le grec à Venise, au séminaire grec, mais pas suffisamment pour pouvoir le parler et le lire. Il rencontre aussi sur la lagune le starets Rouvim, originaire de Kiev comme lui, qui devient son maittre et son compagnon dans la suite du voyage. Arrivé au Mont Athos, il s'y voit reprocher son costume de pèlerin franc, son parler latin et son ignorance du grec (p. 156). Quand son pèlerinage à Rome s'ébruite, il est accusé d'hérésie et ne peut bénéficier de l'hospitalité que grâce à l'intercession de son starets, après imposition d'une pénitence (p. 175).

En Orient, il retrouve un pluralisme confessionnel interchrétien, mais vécu cette fois sur le mode agressif. À Jérusalem, toutes les communautés rassemblées dans la basilique de la Résurrection chantent dans leur langue, mais «l'orgue sans âme » des « Romains » couvre toutes les voix (p. 259). À Bethléem, des chrétiens de rite grec sont passés au catholicisme, séduits d'après lui par les aumônes et l'or des franciscains (p. 243). Alors qu'il avait visité Lorette avec dévotion, et cru au transport miraculeux de la maison de la Vierge (p.54), il dénonce celui-ci comme un «mensonge» des « Romains » lorsqu'il est à Nazareth, avec un argument qui se veut rationnel : il avait noté que la maison de Lorette était en briques, alors qu'en Palestine, on ne construit qu'en pierres (p. 385). Mais il fait erreur : en réalité, la maison de Lorette est bien en pierres... Au Mont Liban, il est introduit de plain-pied dans le conflit violent qui déchire alors les melkites (grecs) d'Antioche, entre uniates et orthodoxes. Il témoigne de la volonté des moines grecs catholiques d'élever une frontière dogmatique entre eux et les orthodoxes. En effet, ils l'accueillent aimablement, mais le soumettent systématiquement à des controverses théologiques qu'il n'aime pas (p. 321, 324, 325). À Baalbeck, où uniates et orthodoxes se disputent l'église, il invoque Dieu pour mettre fin "à la haine et à la discorde" (p.347). Dans l'ensemble, ce qu'il reproche aux catholiques, c'est moins leurs croyances et leurs pratiques que leur rupture de la communion.

10 Il devient ensuite témoin et acteur de la contre-offensive orthodoxe en Syrie, qui se traduit par l'installation d'un clergé chypriote à la suite du patriarche orthodoxe d'Antioche Sylvestre le Chypriote, et par l'ouverture d'une école à Alep, puis à Tripoli. Dans cette dernière ville, il rencontre un maître, Jacques de Patmos, sous la férule duquel il étudie le grec pendant deux périodes de 10 mois et 8 mois, entrecoupées d'une mission en Égypte, sans doute pour collecter des aumônes, en 1730 (p. 390). Il circule ensuite dans l'Archipel, avant de gagner Patmos où il a été envoyé "à cause des tourments causés à la juridiction d'Antioche par les Papistes et les uniates » (p. 432). Il y rencontre le hiérodiacre Macaire, qui a développé sur l'île un enseignement renommé et gratuit, dont il détaille le programme, attirant des étudiants de tout le monde grec (p. 412, 527). Après son retour à Tripoli, l'école de Jacques de Patmos est transférée à Damas, dans la résidence du patriarche Sylvestre, dans une atmosphère de violence entre catholiques et orthodoxes. C'est là qu'il est consacré sous-diacre et moine par le patriarche lui-même (1734), qui l'aimait "ainsi qu'un père aime son fils ». Il est alors intégré dans le clergé instruit orthodoxe, et évoque à plusieurs reprises les écoles qu'il rencontre sur son chemin dans les monastères. Il passe l'année suivante à Chypre où, durant l'hiver, il est appelé à enseigner le latin à la résidence de l'évêque de Nicosie. Bloqué sur l'île pendant des mois du fait de la peste, il en profite pour la parcourir dans tous les sens, en décrivant de façon précise une cinquantaine de monastères. Macaire de Patmos l'avait convaincu d'étudier le grec pour le profit de son pays natal. Il revient sur l'île en 1737, au moment de la mort du maître, mais y reste ensuite six ans pour y étudier et y enseigner (p. 528-533). La guerre russo-turque de 1735-1739 semble avoir 
considérablement amélioré l'image des Russes parmi les sujets grecs de l'Empire ottoman. Appelé au service de l'ambassadeur de Russie à Constantinople, Barski change définitivement de statut, et de vagabond de Dieu, il devient aux yeux des moines grecs qu'il rencontre une porte d'entrée dans les grâces du Tsar.

11 Finalement à travers le récit de ses errances, des épreuves de la route, des rencontres et des expériences, Barski nous livre un tableau dynamique du monde orthodoxe en train de se renforcer par la construction et la restauration de monastères, le développement de l'enseignement et l'intensification des circulations entre ses différentes composantes, à l'heure de l'exacerbation du conflit entre uniates et anti-romains.

12 Si on peut exprimer un regret concernant cette traduction, c'est la faiblesse des informations contextuelles, ce qui conduit parfois à des erreurs. Il est dommage, par exemple, que le «Ratseli » de Barski à Rome n'ait pas pu être identifié par l'éditrice avec l'Araceli, sur la colline du Capitole (p. 85). La résidence d'un consul de France à Jaffa en 1726 nous paraît sujette à caution, de même que la présence d'un capucin dans cette ville, sur un territoire réservé aux Frères Mineurs (p. 191). Tartous (en Syrie actuelle) ne peut se situer entre Haïfa et Césarée de Palestine (p. 188). La traduction parle de «remonter le Nil » entre Le Caire et Damiette, alors qu'il s'agit bien sûr de le descendre, du sud vers le nord (p. 317). À la page suivante, il est question de naviguer de l'Égypte vers Sidon, avec une escale à Damas au bout de trois jours, ce qui n'est évidemment pas possible. 